\title{
Arbor
}

\section{La significación de las Plazas en la Evolución Histórica de la Trama urbana de la Ciudad de Córdoba}

\author{
M. Loma Rubio, F. Valverde Fernández y \\ C. Sequeiros Pumar
}

Arbor CLXVI, 654 (Junio 2000), 297-309 pp.

La ponderación del legado patrimonial es uno de los valores más en boga en la sociedad actual, como lo demuestra la importancia y el desarrollo que va alcanzando con el paso del tiempo el concepto de patrimonio.

Éste ha evolucionado mucho en los últimos tiempos y de ser en sus inicios un concepto que abarcaba fundamentalmente a obras de arte singulares, únicas y antiguas, ha pasado a incluir todo el legado que hemos heredado del pasado y en el que intervienen elementos artísticos, históricos, geográficos, antropológicos, populares, floklóricos, gastronómicos, etc.

En este contexto, la ciudad ha pasado de ser un ámbito en el que se ubicaban elementos patrimoniales aislados a ser un todo con valores patrimoniales. En este sentido consideramos que la trama urbana es un valor en sí, en el que junto a los elementos que se consideraban aislados anteriormente se ha pasado a valorar la propia trama como un patrimonio que hemos heredado y que debemos cuidar y transmitir.

En lo que a la ciudad de Córdoba se refiere, el valor patrimonial de su trama urbana es algo indiscutible y no en vano ha tenido su refrendo institucional cuando gran parte de la ciudad ha sido declarada Patrimonio de la Humanidad. En este reconocimiento ha jugado un importante papel su casco histórico, muy extenso y relativamente bien conservado, que viene siendo considerado como uno de los mejores ejemplos del urbanismo hispanomusulmán. 
Actualmente, y sin entrar a considerar anteriores procesos evolutivos, este casco histórico es el producto de la evolución que ha sufrido esta zona desde la reconquista de la ciudad en 1236 hasta la actualidad.

Dicha evolución ha dado lugar a un todo urbano complejo al que el devenir de los acontecimientos históricos ha estructurado en una realidad multiforme.

Así, constatamos la presencia de una clara dualidad morfofuncional entre el recinto intramuros de la ciudad (casco histórico) y la expansión «reciente» extramuros o periferia.

Por otro lado, el casco histórico o la ciudad tradicional se organiza a su vez con una gran complejidad interna al haber funcionado a lo largo de un considerable período histórico como un recinto urbano doble: la Villa, su mitad occidental y la Ajerquía, su parte oriental.

Esta complejidad del recinto intramuros se acentúa por la evolución morfológica y funcional de cada una de esas partes integrantes.

Así, en la Villa, su cuadrante noroccidental ha sufrido una amplia transformación reciente en su trama urbana por las llamadas operaciones de ensanches y transformaciones burguesas, que la hacen distinta de la parte suroccidental de la misma Villa, hoy identificada bajo el término de Judería.

Del mismo modo, el papel jugado en siglos precedentes por el río Guadalquivir ha contribuido a configurar también determinados aspectos morfofuncionales de la parte meridional de la ciudad intramuros, tanto en la propia Villa como en la Ajerquía. No es mera casualidad la ubicación junto al río de algunos de los edificios más representativos de la ciudad, la Mezquita y el Alcázar, sede de los poderes civil y religioso, así como que durante siglos, y mientras el río fuera navegable, se ubicaba en esta zona el centro comercial y artesanal, en definitiva funcional, de la ciudad.

La orla periférica de expansión extramuros de la ciudad tampoco tiene una uniformidad en su estructura urbana, por cuanto su proceso de configuración ha respondido a modos de asentamiento muy distintos, teniendo presente que su desarrollo es fundamentalmente obra de este siglo. Sin restarle importancia al desarrollo urbano actual de la ciudad de Córdoba, los objetivos que subyacen en la génesis de este artículo nos llevan a centrar nuestro trabajo sobre el recinto intramuros, no considerando en estas reflexiones la significación de la ciudad reciente.

En esta trama urbana cambiante la plaza, como elemento singular, tiene también un importante significado, por considerar que en ella encontramos multitud de elementos que nos ayudan al conocimiento del patrimonio urbano. En la ciudad, la plaza se nos revela como uno 


\section{La significación de las Plazas en la Evolución...}

de los elementos de más singular significación de los que constituyen la trama urbana, por haberse erigido en símbolo, a través de la historia, de la vida de la propia ciudad y haber reunido en ella a lo largo del tiempo algunos de los elementos patrimoniales más singulares y representativos de la memoria colectiva de sus habitantes.

Pero además de este valor patrimonial, las plazas deben ser consideradas un elemento dinamizador de la evolución de la trama urbana cordobesa y posiblemente de la de otros cascos históricos. En el caso que nos ocupa, los cambios en el urbanismo cordobés han sido constantes, aunque hemos de reconocer que los de mayor significación han sido los acaecidos en la segunda mitad del siglo XIX y en las primeras décadas del XX, que transformaron el sector noroccidental de la Villa (ensanche y transformaciones burguesas). Hasta entonces las modificaciones ocurridas en la trama urbana de la ciudad fueron, como decimos, de escasa importancia y en ellas jugaron un papel fundamental las plazas, ya que los cambios ocasionados por la apertura de unas y las remodelaciones o desaparición de otras, fueron los factores que determinaron los cambios más importantes acaecidos en la trama urbana cordobesa desde los siglos XIII al XIX.

$\mathrm{Al}$ análisis de esos cambios en la ciudad de Córdoba y al de las diferentes causas que los explican y del papel que en ellos jugaron los diferentes agentes sociales que los posibilitaron dedicamos las reflexiones siguientes.

1. En primer lugar hemos constatado como la trama urbana se ha visto modificada con la desaparición de algunas plazas o la disminución de otras, por las apropiaciones realizadas en su superficie por particulares o instituciones.

Este fenómeno, que puede constatarse durante toda la Edad Moderna, se iniciaba con la solicitud por parte de un particular, generalmente un noble o persona destacada o también una institución religiosa, de un trozo del espacio público de la plaza que, de ser concedido, era incorporado a sus inmuebles.

Lo corriente era que las solicitudes afectaran a pequeñas porciones de terreno, y solían tener una respuesta favorable por parte del municipio siempre que, tras realizar un examen del lugar los peritos del ayuntamiento, éstos acreditaran que la cesión no perjudicaba a terceros.

Estas solicitudes se justificaban, en la mayoría de los casos, apelando al bien común, ya que casi siempre se pedía la anexión de rincones o callejas sin salida que, dados los hábitos de higiene urbana propios de épocas pasadas, se convertían con frecuencia en muladares que atentaban contra la salud pública. En las peticiones, además de poner 
de manifiesto los interesados el beneficio que la cesión ocasionaría a la comunidad, ya que con ella se terminaba con un lugar malsano y un posible foco de infecciones, también era frecuente que se apelara a la mejora urbanística que suponía quitar callejones y rincones, pues de esta manera se iría logrando poco a poco un trazado viario más regular y racionalizado de la ciudad.

En muchas ocasiones el proceso terminó con la cesión por las autoridades municipales de parte de la vía pública en favor de los solicitantes.

Los ejemplos que ilustran lo que venimos diciendo son abundantes.

Así, en la actual plaza de San Ignacio de Loyola, situada junto a la Real Colegiata de San Hipólito, fundación de Alfonso XI en 1343 para Panteón Real, se produce uno de esos procesos de apropiación de pequeñas porciones de espacio público. Ello tiene lugar en febrero de 1772 cuando el obrero de la Colegiata realiza una solicitud por la que pedía al cabildo municipal se le concedieran los dos rincones que había junto a «las dos capillas colaterales a la mayor, para construir dos capillas nuevas y en las dos diagonales que causan hasta el testero de la misma, dos atarazanas, quitando del todo el daño que se sigue de los rincones y no estorbando como no se estorba el paso libre para todo carruaje».

El veredicto del maestro de obras de la ciudad fue favorable, por lo que se concedió la gracia solicitada y el templo se amplió unas 240 varas cuadradas a expensas del terreno público ${ }^{1}$.

Un ejemplo similar encontramos en la vecina plaza de San Nicolás de la Villa, donde se ubica una de las catorce parroquias fundadas por Fernando III tras la conquista de la ciudad. El templo de San Nicolás es un importante ejemplo de las iglesias gótico-mudéjares cordobesas, cuya torre, una de las más bellas de la ciudad data de fines del XV.

En el espacio que rodeaba al muro norte de la iglesia, a mediados del siglo XVI, con motivo de la construcción de su espléndida capilla del bautismo, se desplazó dicho muro hacia el exterior, ocupándose así parte de la plazuela a la que se abrió una nueva portada de traza renacentista.

Posteriormente, entre 1771 y 1773 , se repitió el mismo hecho, aunque ahora el muro desplazado fue el occidental, que avanzó una vara, cedida por las autoridades locales, a lo largo de la calle de la Torre, con lo que se amplió el espacio para ubicar el coro y se cegó la primitiva portada principal del templo ${ }^{2}$.

Algo parecido había ocurrido en la plaza de San Miguel, también ubicada en la Villa, y en la que se levanta la iglesia del mismo nombre, 
otro bello ejemplo de las iglesias gótico-mudéjares cordobesas. Dicho templo sufrió una ampliación en su testero norte, como consecuencia de la solicitud que la compañía del Santísimo Sacramento hizo al cabildo municipal para que le concediera un trozo de vía pública para ensanchar la capilla de San Antonio, con lo que se conseguiría «un piadoso fin, con más hermosura de la calle, sin perjuicios del común ni impedir el paso de coches, carros ni bestias». Esta solicitud fue concedida en el cabildo del 20 de octubre de $1760^{3}$.

En otros casos la apropiación de espacio público en las plazas fue de mucha mayor envergadura, como ocurrió en la del Potro, cuyo perímetro se redujo sensiblemente, o en la de las Yeguas, que desapareció por completo.

La plaza del Potro, situada en la collación de San Nicolás de la Axerquía, y en las inmediaciones del Guadalquivir, vio reducida sus dimensiones tras la construcción del hospital de la Caridad a finales del siglo XV. Este edificio se levantó a expensas de la propia plaza que vio reducida su superficie por su lado oriental en más de la mitad. Con esta reforma su solar perdió la forma cuadrangular que hasta entonces presentaba, para ofrecer desde entonces la forma rectangular y alargada que presenta en la actualidad, que le da el aspecto de una calle algo ancha ${ }^{4}$. A pesar de esta importante reducción de su superficie, la plaza del Potro, de amplias resonancias literarias, siguió manteniendo la importancia económica y comercial que en aquellas fechas la caracterizaba y constituye hoy, pese a su sobriedad, una de las plazas más representativas del urbanismo cordobés. Su caserío, de gran sabor popular, acoge, además del antiguo Hospital de la Caridad, que hoy alberga al Museo Provincial y al de Julio Romero de Torres, el edificio de la antigua Posada del Potro, uno de los más antiguos ejemplos de arquitectura popular cordobesa (se remonta al siglo XIV), hoy sede de la Delegación de Cultura del Ayuntamiento de la ciudad. El empaque de la plaza se ve acrecentado con la presencia en ella de uno de los mejores triunfos de San Rafael de la ciudad, obra dieciochesca de Miguel de Verdiguier, y con la popular Fuente del Potro, que le da nombre.

En el caso de la plaza de las Yeguas el proceso de apropiación de espacio público la llevó hasta su desaparición total. Esta plaza estaba situada en la Axerquía, en la mediación de la calle Siete Revueltas, collación de Santiago. Su perímetro formaba un cuadrado de 14 varas de lado, y lindaba por dos de sus costados con los jardines de la casa-palacio de los marqueses de las Escalonias y vizcondes de Miranda. En el cabildo del 12 de septiembre de 1727 se presentó al municipio una petición del mencionado marqués en la que ponía de manifiesto 
que su jardín lindaba con la plazuela de las Yeguas «donde aquella vecindad había hecho un muladar...causando a sus paredes graves perjuicios...», por lo que pedía se le concediese el expresado muladar para incorporarlo a su jardín, y, de esta forma, «dejar en seguridad sus casas». La petición fue aceptada en el cabildo del 28 de noviembre de 1727, por lo que el marqués incorporó a su jardín las 100 varas cuadradas de vía pública de que constaba el mencionado muladar ${ }^{5}$.

Años más tarde, en el cabildo del 15 de julio de 1761, se presentó un memorial de D. Juan de Paniagua, presbítero, por el que se solicitaba al ayuntamiento la concesión de otro pedazo del espacio que quedaba de la plaza de las Yeguas. En este caso se alega al hacer la petición que su casa, estaba situada en las Siete Revueltas en una calleja sin salida «donde se cometen actos inmorales», y por ello solicitaba se le permitiera incorporar a sus casas la citada calleja. El 29 de agosto de 1761, tras haberse efectuado los trámites oportunos, se le concedió lo demandado, por lo que incorporó a su propiedad otras 34'5 varas cuadradas de vía pública ${ }^{6}$. De esta manera, desapareció por completo la plazuela de las Yeguas cuyas 196 varas cuadradas se vieron reducidas a 61 '5, que pasaron a formar parte, pero ya como calle, del conjunto de intrincadas callejas que conforman las Siete Revueltas.

Sin querer ser exhaustivos, queremos poner de manifiesto que existen muchos ejemplos en la ciudad de Córdoba de plazas que desaparecen parcial o totalmente al integrarse su espacio en una propiedad particular. Entre los primeros podemos citar los casos de la plaza del Conde de Gavia, la plaza denominada del Santísimo, sita en las callejas de Alcántara, plaza de la Trinidad, de San Rafael, de Almanzor, del Campo Santo de los Mártires, etc. En el caso de las desaparecidas se encuentran, entre otras, la plazuela del Rehoyo de San Agustín, la de la Barreruela, en la calle Osario, la del Quanto, en la collación de Omnium Sanctorum, etc ${ }^{7}$.

2. En otras ocasiones hemos comprobado que las modificaciones del trazado viario fueron consecuencia de la aparición de plazas o de la ampliación de ámbitos preexistentes por la cesión de espacio para su uso público.

En este caso nos referimos a cambios producidos por particulares quienes, al adquirir ciertas propiedades o remodelar las que poseían, liberan terreno para uso público, movidos habitualmente por intereses personales.

Estos intereses no eran otros que el deseo de los propietarios de facilitar los accesos a sus casas y dar realce a sus propiedades al posibilitar una mejor contemplación de sus fachadas, acrecentando de 
ese modo su valor arquitectónico. Para ello generaban ante ellas una plaza o plazuela que se convertía en antesala de esos edificios.

La importancia que tuvieron las casas-palacio de la nobleza local en la modificación urbanística de su entorno, ha quedado perfectamente documentada en el caso del palacio de los Páez de Castillejo, hoy Museo Arqueológico. Esta casa palacio, uno de los más bellos edificios renacentistas de la arquitectura civil de Córdoba, se ubica en la plaza de Jerónimo Páez, situada en el barrio de la catedral. La plaza presenta en la actualidad unas dimensiones considerables, así como una gran calidad tanto por el valor de varios de los edificios que alberga en su perímetro como por lo elementos ornamentales que se organizan en su espacio libre central.

Y fue, concretamente, la construcción de la casa de los Páez la que motivó la remodelación de parte del trazado urbano de su entorno y la aparición, al menos en proporciones similares a las que presenta en la actualidad, de la plaza que lo alberga.

Ya desde finales del siglo XIII tenemos constancia de la existencia de una plazuela, conocida como plaza de los Paraísos, y de la que también hemos encontrado referencias en la segunda mitad del siglo XIV, en el lugar donde hoy se ubica la de Jerónimo Páez ${ }^{8}$. Esta plaza medieval sería el núcleo de la actual que se desarrollaría gracias a la iniciativa de D. Luis Páez de Castillejo, que fue quién mandó construir el palacio a mediados del siglo XVI.

La magnificencia de la obra y la simbología de la fachada debía contar también con un marco adecuado para poderla contemplar y admirar, lo que posiblemente no posibilitaba las reducidas dimensiones de la primitiva plaza de los Paraísos ${ }^{9}$. Por ello, para que su obra pudiera ser admirada, D. Luis no dudó en adquirir los inmuebles situados en sus inmediaciones para ampliar la primitiva plazuela y crear otra mayor, más acorde con la majestuosidad de su nueva casa, y desde donde ésta se pudiera contemplar. Para realizar esta remodelación D. Luis adquirió una casa horno y otra del convento de Santa Clara, colindantes con la suya, y las derribó, junto con otras que él poseía en aquel lugar, para «hacer plazuela» ${ }^{10}$.

Un proceso similar debió producirse, aunque no lo hayamos podido constatar documentalmente, en la formación de las plazas que existen delante de otras muchas casas palacio. Es el caso de las plazas que se abren delante de las casas de los Condes de las Quemadas (plaza del Ave María), de los Marqueses de la Fuensanta del Valle (plaza de la Lonja de Benamejí) o de los marqueses del Carpio, todas situadas en la Villa, y el de las que se abren también delante del palacio de 
los Villalones, del de los Aguayos o del palacio del Vizconde de Miranda, ubicadas estas últimas en la Ajerquía y denominadas con el nombre de las familias ante cuyo palacio se encuentran. Creemos conveniente señalar que en el caso de la casa palacio de los marqueses del Carpio, a pesar de que existe el espacio abierto delante de la misma, dicho espacio nunca ha sido denominado plaza.

En todos los casos se conservan ejemplos de magníficas casas señoriales, las que suponemos que contribuyeron a originar las respectivas plazas, aunque la mayoría de ellas ya no son de titularidad particular y han sido dedicadas a otros usos. Así, la antigua casa de los Condes de las Quemadas acoge hoy las instalaciones de la Escuela de Danza, la de los Marqueses de la Fuensanta del Valle es la sede del Conservatorio, la de los Villalones se encuentra en fase de remodelación para albergar en ella actividades de tipo cultural, la de los Aguayos es desde hace mucho tiempo sede de un centro educativo y la de los Vizcondes de Miranda fue hace tiempo remodelada, conservando solamente su fachada y vaciando su interior reconstruyéndolo como edificio de apartamentos.

El mismo fenómeno de creación de una plaza se repite, aunque en este caso priman más los motivos prácticos (de facilitar acceso a un edificio y no tanto otros motivos ornamentales o de ostentación), en el caso de la plaza del Padre Cristóbal, en el barrio de San Agustín, que fue abierta por la cofradía de Jesús Nazareno para que «volviesen los carruajes» y pudiesen acceder al Hospital del mismo nombre ${ }^{11}$.

3. Por último, hemos encontrado otra serie de ejemplos en los que la aparición, desaparición o remodelación de las plazas de la ciudad estuvo motivada por la actuación de los poderes públicos con el fin de dotar a Córdoba de espacios más abiertos en zonas donde la red urbana era especialmente tupida, para satisfacer las carencias de espacios lúdicos e institucionales que presentaba la ciudad, o para dejar exento y hermosear alguno de sus monumentos más significativos.

Las intervenciones que por estos motivos realizaron las autoridades locales en la ciudad supusieron, en la mayoría de los casos, grandes rupturas en la trama que fueron proporcionalmente más significativas hasta la segunda mitad del siglo XIX. A partir de esa fecha las plazas pierden el protagonismo que hasta entonces habían tenido como elementos dinamizadores de la evolución de la trama urbana, y lo cedieron a las grandes intervenciones urbanas realizadas durante la segunda mitad del siglo XIX y las primeras décadas del XX, para abrir la ciudad y modernizarla, y a la posterior expansión urbana acaecida después de la Guerra Civil que, como decimos, acabaron convirtiéndose 
en los elementos fundamentales que explican la evolución y el desarrollo urbano cordobés de los últimos tiempos.

En las intervenciones realizadas por las autoridades locales en relación con las plazas cordobesas, pueden, por tanto, señalarse dos períodos claramente diferenciados, el primero que llegaría hasta mediados del siglo XIX, y otro que desde esa fecha abarcaría hasta la actualidad.

3.1. En el primero de dichos períodos las plazas que se abren o amplían mediante una remodelación expresa del casco, suelen ser de medianas o grandes proporciones, y presentar una forma geométrica bastante regular que generalmente es el cuadrado o el rectángulo, siendo las más significativas la de San Agustín (que se abre delante de la Iglesia del convento de su mismo nombre), la de Abades (en las proximidades de la Mezquita Catedral) o la de las Cañas (situada en la parte trasera de la plaza de la Corredera de la que funciona como antesala).

La plaza de la Corredera podría ser considerada como la más significativa de este proceso, ya que fue creada expresamente para que sirviera de plaza mayor y funcionara como el corazón institucional de la ciudad.

La creación de la plaza actual es obra de fines del siglo XVII y decisión del corregidor Ronquillo Briceño. Su diseño supuso la ruptura de la trama urbana anterior partiendo de una plaza preexistente que ya aparece mencionada en la documentación del siglo XIII.

La plaza se organizó, siguiendo las trazas barrocas, como un recinto de 5.550 metros cerrado por una edificación de tres plantas sobre soportales de arcos de medio punto, y se convirtió oficialmente en el centro cívico de la ciudad ya que albergaba las casas del corregidor, la cárcel pública y el pósito, y en ella se celebraban fiestas de toros $\mathrm{y}$ otros muchos actos públicos ${ }^{12}$.

3.2. En el segundo período el número de plazas abiertas por remodelación expresa del casco urbano es mayor que en el anterior, pero a pesar de ello las plazas pierden el protagonismo que hasta entonces habían tenido en la evolución del urbanismo cordobés. A partir de la segunda mitad del siglo XIX los cambios acaecidos en la trama urbana de Córdoba son tantos y de tal envergadura, que la apertura, desaparición o remodelación de plazas son uno más, pero no, como ocurría hasta entonces, el más significativo.

La aparición de la mayoría de estas plazas son hijas del deseo de crear una ciudad más racional y habitable, donde la apertura de espacios abiertos, los paseos, las rondas y las avenidas eran símbolo de modernidad y exponente de la nueva concepción urbana de la clase emer- 
gente en Europa, la burguesía, cuya concepción de la ciudad suponía una ruptura con la realidad urbana heredada de siglos pasados.

Los grandes cambios que se realizaron en la trama urbana durante el siglo XIX estuvieron posibilitados por las desamortizaciones, otro fenómeno de corte liberal y burgués que liberó gran cantidad de suelo que pudo ser reutilizado en las transformaciones urbanas que caracterizaron a este período.

Como consecuencia de este deseo modernizador y de apertura de la ciudad, y del proceso desamortizador, son varias las plazas que surgen o se remodelan en la ciudad, entre la que destacamos las siguientes: San Bartolomé, Cardenal Toledo, Mármol de Bañuelos, Emilio Luque, Puerta del Puente, Judá Leví, Tierra Andaluza o Juan Bernier.

Quizá uno de los ejemplos más significativos de cómo influye el fenómeno de la desamortización en la apertura de nuevas plazas sea el caso de la del Cardenal Toledo. La apertura de esta plaza data de 1868, año en que fue suprimido el Convento de las Dueñas ${ }^{13}$. El 11 de octubre de 1869 el Cabildo aprobó la propuesta del arquitecto municipal de demoler el ángulo del citado convento de las Dueñas que quedaba entre las calles del Císter y de la Panadería. Con el terreno liberado de esta manera se crearía una nueva plaza que serviría para desahogo y embellecimiento de esta zona de la ciudad y para dar luz al cuartel que se proyectaba instalar en el edificio conventual, que permanecía casi íntegro ya que el terreno enajenado para formar la plaza fue el de los corrales ${ }^{14}$. Tras varios proyectos de reordenación de este espacio presentados en 1883 y 1895, la plaza adquirió su fisonomía definitiva en 1945, fecha desde la que se convirtió en uno de los más bellos y románticos parajes de la trama urbana cordobesa.

Continuando con este mismo espíritu reformista propio de la segunda mitad del siglo XIX, pero sin relación con el proceso desamortizador, se abren otras plazas dentro del casco histórico de la ciudad. Un claro ejemplo sería el de la ampliación de la plaza de Mármol de Bañuelos. El fenómeno se produce en 1895 cuando se derribó, no sin ardua polémica, la casa solariega de los Bañuelos para alinear la calle Diego de León, con lo que se incrementó casi al doble el espacio de la plaza originaria ${ }^{15}$.

La misma filosofía modernizadora produjo también el efecto contrario, es decir, la desaparición de algunas plazas, que se perdieron en el proceso de ensanche de la trama urbana. Es el caso de la antigua plaza de la Moneda, sita junto a la trasera de la Real Colegiata de San Hipólito, y que desapareció en el proceso de confi- 
guración de la Avenida del Gran Capitán, que fue la actuación más emblemática del proceso de ensanche burgués acaecido en la ciudad de Córdoba ${ }^{16}$.

Otro fenómeno también característico del siglo XIX fue la apertura o ampliación de plazas a costa de los desaparecidos cementerios de las diferentes parroquias de la ciudad, que se trasladaron a las afueras del ámbito urbano por razones de higiene y salud pública. Este es el caso en nuestra ciudad, entre otras, de las plazas de San Nicolás de la Villa, San Miguel o San Pedro.

En otros casos, la remodelación de la plaza responde a la intención de dignificar el monumento que alberga. El caso de la plaza de la Puerta del Puente, situada junto al flanco meridional de la Mezquita Catedral y ante el río Guadalquivir, ilustra lo que decimos.

Dado el carácter ruinoso y lamentable que presentaba este monumento, desde mediados del siglo pasado se alzaron voces en pro de su consolidación, y el primer proyecto al respecto apareció en 1853 gracias a la iniciativa del arquitecto D. Pedro Nolasco ${ }^{17}$. Después de éste, reiterados proyectos se sucedieron a lo largo de las décadas de los cincuenta y sesenta, y se vuelven a plantear a finales del siglo. En 1895, en un nuevo proyecto que se encarga, se contempla explícitamente la remodelación del lugar dejando la puerta exenta y flanqueada por dos calles laterales de circunvalación.

El proyecto sufrió un nuevo aplazamiento hasta que definitivamente, en 1912, se retoma la idea gracias a los esfuerzos de Enrique Romero de Torres, y al interés del alcalde Salvador Muñoz Pérez, lo que permitió que en los años sucesivos el lugar adoptase la fisonomía que con pequeñas variantes ha llegado hasta nuestros días ${ }^{18}$.

Por último y ya en un proceso ajeno a las intenciones decimonónicas de la remodelación del casco histórico, también en este siglo se han abierto algunas plazas de entre las que por su envergadura espacial queremos destacar la de Juan Bernier.

Esta plaza surge como consecuencia de la demolición de un edificio singular de carácter monumental, el convento de Santa María de Gracia. En esta actuación urbanística encontramos una nueva concepción en la intervención de los poderes locales. Aunque el convento se había demolido con intenciones especulativas, la ciudad se había sensibilizado ya en el respeto hacia el pasado, y pretendía guardar memoria histórica de sus monumentos, por lo que el ayuntamiento anula la intervención especulativa y decide la construcción de una plaza que ocupa parte del solar del antiguo convento. En ella, aprovechando parte de la antigua portada del edificio, salvada de la demolición, se urbanizó un amplio 
espacio, circundando por una media arcada a la manera de pérgola, que recuerda la disposición del antiguo claustro.

Con los cambios anteriormente descritos creemos que se pone de manifiesto el importante papel que las plazas han jugado a lo largo del tiempo en la configuración y evolución del casco histórico de la ciudad de Córdoba, esa realidad urbana que a pesar de los cambios sufridos ha sabido mantener su singularidad y atractivo a lo largo del tiempo.

\section{Notas}

1 ARCHIVO MUNICIPAL DE CÓRDOBA (A.M.CO.), sección 8, serie 5, legajo 766, documento 54. Otros análisis de los procesos de transformación de la trama urbana de la ciudad de Córdoba, en relación con sus plazas, han sido abordados por nuestro grupo de trabajo en M. Loma, C. Sequeiros y F. Valverde: «Reflexiones acerca del papel que ciertos monumentos han jugado en la evolución de la trama urbana de la ciudad de Córdoba", comunicación presentada a las II Jornadas de Patrimonio. Patrimonio y Ciudad, Priego de Córdoba, 1993 y F. Valverde, M. Loma y C. Sequeiros: "Algunas transformaciones en la trama urbana de Córdoba: la apropiación de espacio público en las plazas» en F. García Verdugo y F. Acosta Ramírez (Coords.): Córdoba en la Historia: la construcción de la Urbe (Actas del Congreso), Córdoba, 1999, 349-356.

2 Archivo de la Catedral de Córdoba, Libro de Cuentas de San Nicolás de la Villa, 1765-1774, año $1774, \mathrm{n}^{\circ} 29$.

3 A.M.CO., sección 8 , serie 5 , caja 766 , documento 33 .

4 J. M. Escobar Camacho: "Posadas y mesones en la Córdoba bajomedieval», en B.R.A.C. (Córdoba), 103 (1982), 132-133; T. Ramírez de Arellano: Paseos por Córdoba, o sean apuntes para su historia, Córdoba, 1981, 267.

5 A.M.CO., sección 8, serie 5, legajo 766, documento 17.

6 A.M.CO., sección 8, serie 5, legajo 766, documento 34; T. Ramírez de Arellano: Paseos por Córdoba..., 197 y 238.

7 Información sobre este fenómeno puede encontrarse en A.M.CO. sección 8, serie 5, caja 766, documentos 35, 39, 45, 49, 50, 53, 56, 67, 68; T. Ramírez de Arellano: Paseos por Córdoba..., 101 y 357, y F. Valverde, M. Loma y C. Sequeiros: "Algunas transformaciones en ...", 349-356.

8 J.M. Escobar Camacho.: Córdoba en la Baja Edad Media, Córdoba, 1989, 139-140.

9 Sobre el valor simbólico de la fachada de este edificio, véase S. Sebastián: Arte y Humanismo, Madrid, 1978, 81.

10 A.M.CO., sección 8, serie 5, legajo 767. Esas otras casas de D. Luis a la que hace referencia el documento anterior posiblemente sean tres casas que dicho señor compró en noviembre de 1554 a sus hermanas, doña María de Valenzuela y doña Juana de Guzmán, "para hacer la plazuela que está delante (de sus casa)", por un valor total de 6.000 ducados, R. Ramírez de Arellano: Inventario monumental y artístico de la provincia de Córdoba, Córdoba, 1982, 217.

11 T. Ramírez de Arellano: Paseos por Córdoba..., 69. 


\section{La significación de las Plazas en la Evolución...}

12 Sobre esta plaza existe una abundante bibliografía entre la que cabe destacar: M. Yllescas Ortiz: La plaza de la Corredera de Córdoba, Tesis de licenciatura, Universidad de Sevilla, 1981, inédita; M. Yllescas Ortiz: «Evolución urbanística de la plaza de la Corredera", Axerquía (5, 1982); M. D. Catalán Burón y otros: Plaza de la Corredera: Plan especial de protección. Ayuntamiento de Córdoba, Córdoba, 1982; F. Quesada Ríos: "La obra y nueva fábrica de la plaza de la Corredera de Córdoba (1683-1687)", en Actas II Coloquio de Historia de Andalucía. Andalucía Moderna II, Córdoba, 1983, 355-373; M.D. Catalán Burón y otros: La Corredera, Córdoba, 1986.

13 C. Martín López: Córdoba en el siglo XIX. Modernización de una trama histórica, Córdoba, 1990, 361.

14 A.M.CO., Sección 8, Serie 5, Caja 768, Documento 115.

15 C. Martín López: Córdoba en el..., 389-426.

16 La génesis y la evolución del paseo del Gran Capitán han merecido la atención de los estudiosos del urbanismo cordobés, entre los que destacan los realizados por F. García Verdugo: Córdoba, Burguesía y Urbanismo. Producción y Propiedad del Suelo Urbano: El Sector de Gran Capitán, 1859-1936, Córdoba, 1992; C. Martín López: Córdoba en el..., 159-165, 224-229, y 476-477; y T. Ramírez de Arellano: Paseos por Córdoba... 333 y 335.

17 C. Martín López: Córdoba en el..., 73-76.

18 Ibíd., 265-268. 